\title{
FAST COMPUTATION OF SHIELDING EFFECTIVENESS OF METALLIC ENCLOSURES WITH APERTURES AND INNER ELEMENTS
}

\begin{tabular}{|c|c|}
\hline Journal: & Microwave and Optical Technology Letters \\
\hline Manuscript ID: & draft \\
\hline Wiley - Manuscript type: & Research Article \\
\hline \multicolumn{2}{|l|}{$\begin{array}{r}\text { Date Submitted by the } \\
\text { Author: }\end{array}$} \\
\hline Complete List of Authors: & $\begin{array}{l}\text { Lozano-Guerrero, Antonio; Polytechnic University of Cartagena, } \\
\text { Information Technologies and Communicactions } \\
\text { Diaz-Morcillo, Alejandro; Polytechnic University of Cartagena, } \\
\text { Information Technologies and Communicactions } \\
\text { García-Fernández, Miguel; Polytechnic University of Cartagena, } \\
\text { Information Technologies and Communicactions } \\
\text { Balbastre-Tejedor, Juan; Polytechnic University of Valencia, } \\
\text { Communications }\end{array}$ \\
\hline Keywords: & $\begin{array}{l}\text { Shielding effectiveness, enclosure, radiated interference, printed } \\
\text { circuit board, conductive composite }\end{array}$ \\
\hline
\end{tabular}

\section{s ScholarONE" \\ Manuscript Central}




\title{
FAST COMPUTATION OF SHIELDING EFFECTIVENESS OF METALLIC ENCLOSURES WITH APERTURES AND INNER ELEMENTS
}

\author{
Antonio José Lozano-Guerrero, ${ }^{1}$ Alejandro Díaz-Morcillo, ${ }^{1}$ Miguel Ángel García- \\ Fernández, ${ }^{1}$ and Juan Vicente Balbastre-Tejedor ${ }^{2}$ \\ ${ }^{1}$ Departamento de Tecnologías de la Información y las Comunicaciones \\ Universidad Politécnica de Cartagena \\ Cartagena, Spain \\ ${ }^{2}$ Instituto ITACA \\ Universidad Politécnica de Valencia \\ Valencia, Spain \\ email: antonio.lozano@upct.es \\ Fax: +34 968325973
}

\begin{abstract}
In this study, radiated immunity and emission of a metallic box with apertures have been evaluated through a fast approach. The influence of printed circuit boards inside the enclosure has been studied and also the effect of placing conductive polymer sheets in the housing in order to characterize the behaviour of these materials used nowadays for shielding cabinets. Measurements have been carried out in anechoic chamber in order to evaluate the approximated technique showing its limitations and advantages. Since good agreement has been found between simulations and measurements, this approach can be used for design or optimization purposes with the main advantage of reduced time calculations.
\end{abstract}

Key words: Shielding effectiveness; enclosure; radiated interference; printed circuit board; conductive composite 


\section{INTRODUCTION}

Electronic systems are generally housed in an enclosure with many functions: physical protection, aesthetic image, electromagnetic shielding; this last feature is of particular relevance in environments where the electromagnetic spectrum is polluted by many radiating sources, being high speed digital circuitry one of the most important sources of interferences.

Many authors have analyzed the effect of apertures on a metallic enclosure surface with the presence of electromagnetic interferences (EMI) using different techniques. In [1] an analytical shielding theory for metallic enclosures with apertures for frequencies below the first cavity resonance was obtained. Another analytical model [2] provides fast results for empty cavities but it also has frequency limitations. Analytical solutions are very fast but cannot deal with inner arbitrary elements. Full wave simulations through numerical methods allow arbitrary configurations with various apertures and inner elements to evaluate the effect of printed circuit boards (PCBs) or absorbers, but computational cost is too high and optimization or design procedures require long computation times. In [3] the Method of Moments was applied to obtain the shielding effectiveness of a metallic enclosure with more than one aperture, taking into account the effect of inner contents as metallic plates or absorbers. The Finite-Difference TimeDomain (FDTD) method for the study of the shielding effectiveness of a metallic box with apertures is evaluated in [4-5]. The analysis of inner elements, especially PCBs, has been realized through several tools. In [6] results obtained through a semi-analytical tool show how it can be modelled as a homogeneous lossy material backed by a metallic plate. In [7-8] the PCBs are evaluated as metallic plates. The study of damping cavity resonances through lossy materials has been carried out in [9]-[11]. In [12] a previous work to study the damping of resonances through conductive polymers was presented.

The use of conductive polymers in the manufacturing of enclosures to protect electronic devices from electromagnetic interferences has become a very interesting alternative to traditional metallic cabinets. However little information has been reported regarding the behaviour of these materials in enclosure configurations. Plastic materials have many advantages over metallic ones: plastics are lighter, there are no problems associated with corrosion and, for mass production, the fabrication process and the final product becomes cheaper. In this paper, the insertion of conductive polymers in a metallic enclosure has been analyzed.

In this study a 2-D approximated method is used to evaluate the radiated immunity and emission of empty enclosures and with inner elements. The 2-D technique is able to model any content of the cavity as long as vertical invariance of the structure under study remains unchanged.

\section{THEORY}

Shielding effectiveness for a particular shielding configuration is defined as the ratio between the field in the selected placement without enclosure and the field with the enclosure. In this study the shielding effectiveness has been obtained for the electric field:

$$
S E(\mathrm{~dB})=20 \log _{10}\left|\frac{E_{i}}{E_{t}}\right|
$$

For radiated immunity analysis a plane wave impinges on the enclosure and the electric field is measured inside the housing. For radiated emission analysis an infinite wire has been modelled. This wire has been located inside the enclosure and acts as the emitting 
source of interferences. SE for this case is obtained as the ratio between the electric field level produced by the wire without the shield $3 \mathrm{~m}$ from the source and the electric field level obtained with the protecting structure at the same point.

As stated before, to evaluate the shielding effectiveness of a metallic enclosure with various apertures in one of its sides a 2-D method is used. This method involves the study of the transversal cut of the structure. In Figure 1 it is depicted the plane under study. The studied case is the most critical for SE due to the horizontal aperture orientation and the vertical incident polarization. The effect of the width of the aperture $w$ is evaluated through the following simple and empirical factor:

$$
S E(\mathrm{~dB})=S E_{2-D}(\mathrm{~dB})+10 \log _{10}\left(\frac{b}{w \cdot n^{2}}\right)
$$

where $b$ is the height of the cavity, $w$ is the width of the aperture, $n$ is the number of apertures and $S E_{2-D}(\mathrm{~dB})$ is the shielding effectiveness obtained for the 2-D configuration through any numerical method. This approach is based on the vertical invariance of the fields and the coupling level is provided by the ratio in (2) between the height of the box and the width of the aperture. The coupling factor assumes the vertical superposition of $b / w$ apertures infinitely close. The influence of $n$ apertures in (2) has been taken from the rule of thumb given in [3], doubling the number of apertures decreases the SE in 6 dBs approximately.

As long as the field distribution is invariant with the vertical dimension, the field can be evaluated for the whole cavity. For locations near the aperture, where vertical invariance is not accomplished and where the approximation (2) is done to evaluate the coupling energy from the outer to the inner part of the cavity, the accuracy of the results decreases. The major drawback of this technique is the limitation to inner elements with invariant vertical distribution. Taking into account all these aspects the 2-D approximation can help to evaluate in a fast way for both immunity and emission configurations: box resonances, PCB effects, absorbing materials properties, etc.

\section{SET UP}

The aluminium enclosure used for all the simulations and measurements has the following dimensions: $30 \times 12 \times 30 \mathrm{~cm}^{3}$. Two apertures $\left(10 \mathrm{~cm} \times 0.5 \mathrm{~cm}^{2}\right.$ and $20 \times 3$ $\mathrm{cm}^{2}$ ) have been analyzed. Electric field values have been obtained in the center and 0.1 $\mathrm{cm}$ from the back wall of the housing.

For the immunity study a vertical plane wave excites the enclosure through the front aperture and the electric field is measured inside the cavity. The emission set up is obtained by implementing a cylindrical source with the radius of the exciting probe inside the enclosure. The field is measured $3 \mathrm{~m}$ away in the normal direction of the aperture. In Figure 2 the placement of the wire for the emission configuration is shown $0.1 \mathrm{~cm}$ from de back wall.

Measurements have been carried out in an anechoic chamber for the immunity case although reciprocal values can be obtained for the emission case [4]. A log-periodic antenna was placed $3 \mathrm{~m}$ away from the box. A $4 \mathrm{~cm}$-long monopole with $0.065 \mathrm{~cm}$ in diameter was mounted in the center of the box. In order to study the influence of the metallic plates a $7.5 \times 12 \times 0.1 \mathrm{~cm}^{3}$ brass piece has been placed inside the box. For the conductive polymer study a polyamide- 6 doped with carbon fiber sheet [13] with $7.5 \mathrm{x}$ $12 \times 0.3 \mathrm{~cm}^{3}$ dimensions has been located in the same manner as the metallic plate. 
Simulations have been carried out with Matlab ${ }^{\circledR}$ 6.5 PDE Toolbox with the aid of the empirical formula (2) to establish a direct comparison with 3-D measurements. It also takes into account the introduction of more than one aperture. Absorbing boundary conditions have been implemented for the simulations, and the values of the field have been taken at the place shown in Figure 2 in the transversal cut of the structure for immunity and emission and in the center of the enclosure for immunity simulations and measurements.

\section{RESULTS}

For Figure 3 the aperture dimensions are $20 \times 3 \mathrm{~cm}^{2}$ and results have been taken for the inner position $0.1 \mathrm{~cm}$ from the back wall of the cavity. Both curves show reciprocal high SE levels as this placement is located far from the maximums and next to the metallic wall where the field must be zero. For the same aperture Figure 4 shows radiated immunity values taken in the center of the enclosure. SE levels have decreased specially for the first resonance frequency whose maximum is placed upon the measurement location. Measurements and simulations show good agreement. For the lower frequency measurements the noise floor produces poorer results [6].

If a metallic plate acting as a PCB is placed $7.5 \mathrm{~cm}$ from the back wall of the enclosure as shown in Figure 2 and the size of the aperture is $10 \times 0.5 \mathrm{~cm}^{2}$ the first resonance will be shifted upwards due to the effective reduction of the housing. In Figure 5 results for the probe placed $0.1 \mathrm{~cm}$ from the back wall show shaper resonances due to the size reduction of the aperture and high levels of SE once again caused by the measurement location. In Figure 6 the radiated immunity comparison between measurements and simulation when the values have been taken in the center of the enclosure agrees. In Figures 7 and 8 instead of a metallic plate a conductive polymer sample of polyamide- 6 doped with carbon fiber has been introduced in the enclosure. To characterize the sample in the simulations the values $\varepsilon_{r}^{\prime}=30$ and $\sigma=10$ have been obtained for the frequency range under study with the help of an impedance/material analyzer Agilent HP 4291A RF and checking inversely with the proposed tool. Once again immunity and emission produce reciprocal values of SE. The behaviour of this material stands between a dielectric without losses and a metallic plate. The first resonance has been damped due to the introduction of losses in the cavity. In figure 8 results for 3-D simulation with ANSYS $^{\circledR}$ commercial software have been included. A time of 0.9 seconds per iteration was needed for the 2-D study and a time of 49.6 seconds per iteration was required for the 3-D study. Both tools work with the Finite Element Method (FEM). Although meshes are not comparable (2-D mesh refinement was higher) calculation times show clearly the benefits of the approximation. Finally a study of resonance suppression versus conductivity values has been carried out for Figure 9 in which minimums of SE for the first resonance taken from $600 \mathrm{MHz}$ to $800 \mathrm{MHz}$ have been depicted for radiated immunity. There is an optimum for resonance damping and is the same for emission and radiation as reciprocal values of shielding effectiveness have been obtained for immunity and emission configurations when the influence of the inner probe does not change the field distribution inside the enclosure.

\section{CONCLUSION}

A fast 2-D tool has been evaluated to study radiated immunity and emission of metallic enclosures with apertures and inner elements. This tool can effectively work as long as enclosure contents remain invariant in the vertical dimension. The study has been 
carried out for the empty cavity, a cavity loaded with a metallic plate implementing a PCB and a cavity loaded with a lossy material as a conductive polymer. For all the cases results of the approximated technique agree with measurements in anechoic chamber. An optimum value of conductivity has been obtained to damp the first resonance of the enclosure. This conductivity can be obtained through conductive polymers used nowadays in shielding configurations varying the concentration of doping additives. The study of the behavior of conductive polymers may help to obtain enclosures with advantages in EMI protection.

\section{ACKNOWLEDGEMENTS}

This work has been funded by Fundación Séneca, Agencia Regional de Ciencia y Tecnología through the project 00700/PPC/04.

The conductive polymer samples were provided by Policomplex S.L. 


\section{REFERENCES}

1. M. P. Robinson, T. M. Benson, C. Christopoulos, J. F. Dawson, M. C. Ganley, A. C. Marvin, S. J. Porter, and D. W.P. Thomas, Analytical formulation for the shielding effectiveness of enclosures with apertures, IEEE Trans Electromag Compat 40 (1998), 240-248.

2. R. Azaro, S. Caorsi, M. Donelli, and G. L. Gragnani, Evaluation of the effects of an external incident wave on metallic enclosures with rectangular apertures, Microwave Opt Technol Lett 28 (2001), 289-293.

3. F. Olyslager, E. Laermans, D. D. Zutter, S. Criel, R. D. Smedt, N. Lietaert, and A. D. Clercq, Numerical and experimental study of the shielding effectiveness of a metallic enclosure, IEEE Trans Electromag Compat 41 (1999), 202-212.

4. S. V. Georgakopoulos, C. R. Birtcher, and C. A. Balanis, HIRF penetration through apertures: FDTD versus measurements, IEEE Trans Electromag Compat 43 (2001), 282-294.

5. Hyun H. Park, Byung W. Kim, Yeon C. Chung, and Joo G. Lee, FDTD analysis of electromagnetic penetration into a rectangular enclosure with multiple rectangular apertures, Microwave Opt Technol Lett 22 (1999), 188-191.

6. D. W. P. Thomas, A. C. Denton, T. Konefal, T. Benson, C. Christopoulos, J. F. Dawson ,A. Marvin, S. J. Porter, and P. Sewell, Model of the electromagnetic fields inside a cuboidal enclosure populated with conducting planes or printed circuit boards, IEEE Trans Electromag Compat 43 (2001), 161-169.

7. W. Wallyn, and D. De Zutter, Modelling the shielding effectiveness and resonances of metallic shielding enclosures loaded with PCBs, Int Symp Electromag Compat, August 2001, 691-696.

8. R. Azaro, S. Caorsi, M. Cosso, G. M. Costini, M. Donelli, R. Ene, G. L. Gragnani, and M. Pastorino, A semianalythical approach for the evaluation of radiated immunity on a printed-circuit board in metallic enclosures, Microwave Opt Technol Lett 27 (2000), 204-207.

9. J. F. Dawson, J. Ahmadi, A. C. Marvin, Reduction of radiated emissions from apertures in resonant enclosures by the use absorptive materials, $8^{\text {th }}$ Int Conf Electromag Compat, Sep 1992, 207-212.

10. T. Yamane, A. Nishikata, and Y Shimizu, Resonance suppression of a spherical electromagnetic shielding enclosure by using conductive dielectrics, IEEE Trans Electromag Compat 42 (2000), 441-448.

11. N. Izzat, G. H. Hilton, C. J. Railton, S. Meade, Use of resistive sheets in damping cavity resonance, Electron Lett 32 (1996), 721-722.

12. A. J. Lozano, A. Díaz, J. V. Balbastre, L. Nuño, A. B. Calvo, and J. Pitarch, Damping of resonances in a metallic enclosure through conductive polymers, $35^{\text {th }}$ European Microwave Conf, Paris, France, October 2005, 1399-1402.

13. LUVOCOM ${ }^{\circledR} 3 / \mathrm{CF} / 30 / \mathrm{EG}$, Technical sheets, Lehmann\&Voss\&Co, Hamburg. 


\section{LIST OF CAPTIONS}

Figure 1 Enclosure under study in immunity configuration

Figure 2 Position of the wire (emission) and the sample (immunity/emission) inside the enclosure

Figure 3 Results for radiated immunity and emission for an empty enclosure with a $20 \times 3 \mathrm{~cm}^{2}$ aperture. Measurement/excitation position at $0.1 \mathrm{~cm}$ from the back wall

Figure 4 Results for radiated immunity for an empty enclosure with a $20 \times 3 \mathrm{~cm}^{2}$ aperture. Measurement position in the center of the enclosure

Figure 5 Results for radiated immunity and emission for a $10 \times 0.5 \mathrm{~cm}^{2}$ aperture with metallic plate $7.5 \mathrm{~cm}$ from the back wall of the enclosure. Measurement/excitation position at $0.1 \mathrm{~cm}$ from the back wall

Figure 6 Results for radiated immunity for a $10 \times 0.5 \mathrm{~cm}^{2}$ aperture with metallic plate $7.5 \mathrm{~cm}$ from the back wall of the enclosure. Measurement position in the center of the enclosure

Figure 7 Results for radiated immunity and emission for a $10 \times 0.5 \mathrm{~cm}^{2}$ aperture with a conductive polymer sample $0.3 \mathrm{~cm}$ thick placed $7.5 \mathrm{~cm}$ from the back wall of the enclosure. Measurement/excitation position at $0.1 \mathrm{~cm}$ from the back wall

Figure 8 Results for radiated immunity for a $10 \times 0.5 \mathrm{~cm}^{2}$ aperture with a conductive polymer sample $0.3 \mathrm{~cm}$ thick placed $7.5 \mathrm{~cm}$ from the back wall of the enclosure. Measurement position in the center of the enclosure

Figure 9 SE minimum for the first resonance frequency for a $10 \times 0.5 \mathrm{~cm}^{2}$ aperture with a conductive sample $0.3 \mathrm{~cm}$ thick, $\varepsilon_{r}^{\prime}=30$ and placed $7.5 \mathrm{~cm}$ from the back wall of the enclosure. Measurement/excitation position at $0.1 \mathrm{~cm}$ from the back wall 


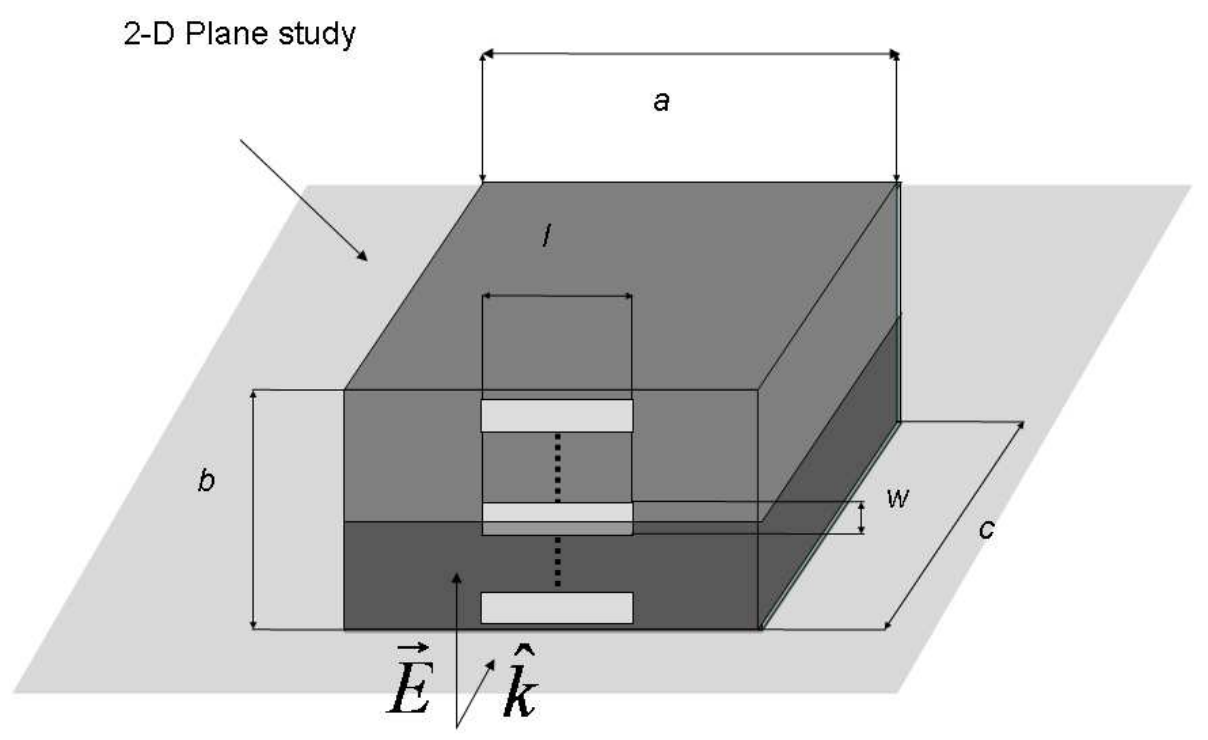

Enclosure under study in immunity configuration $254 \times 190 \mathrm{~mm}$ (96 x 96 DPI) 


\section{Position of the wire (emission) and the sample (immunity/emission) inside the enclosure} $254 \times 190 \mathrm{~mm}(96 \times 96 \mathrm{DPI})$ 
Results for radiated immunity and emission for an empty enclosure with a $20 \times 3 \mathrm{~cm} 2$ aperture. Measurement/excitation position at $0.1 \mathrm{~cm}$ from the back wall $203 \times 152 \mathrm{~mm}(150 \times 150 \mathrm{DPI})$ 
Results for radiated immunity for an empty enclosure with a $20 \times 3 \mathrm{~cm} 2$ aperture. Measurement position in the center of the enclosure $203 \times 152 \mathrm{~mm}(150 \times 150 \mathrm{DPI})$ 
Results for radiated immunity and emission for a $10 \times 0.5 \mathrm{~cm} 2$ aperture with metallic plate $7.5 \mathrm{~cm}$ from the back wall of the enclosure. Measurement/excitation position at $0.1 \mathrm{~cm}$ from the back wall $203 \times 152 \mathrm{~mm}(150 \times 150 \mathrm{DPI})$ 
Results for radiated immunity for a $10 \times 0.5 \mathrm{~cm} 2$ aperture with metallic plate $7.5 \mathrm{~cm}$ from the back wall of the enclosure. Measurement position in the center of the enclosure $203 \times 152 \mathrm{~mm}(150 \times 150 \mathrm{DPI})$ 
Results for radiated immunity and emission for a $10 \times 0.5 \mathrm{~cm} 2$ aperture with a conductive polymer sample $0.3 \mathrm{~cm}$ thick placed $7.5 \mathrm{~cm}$ from the back wall of the enclosure. Measurement/excitation position at $0.1 \mathrm{~cm}$ from the back wall $203 \times 152 \mathrm{~mm}(150 \times 150 \mathrm{DPI})$ 
Results for radiated immunity for a $10 \times 0.5 \mathrm{~cm} 2$ aperture with a conductive polymer sample $0.3 \mathrm{~cm}$ thick placed $7.5 \mathrm{~cm}$ from the back wall of the enclosure. Measurement position in the center of the enclosure

$203 \times 152 \mathrm{~mm}(150 \times 150 \mathrm{DPI})$ 
SE minimum for the first resonance frequency for a $10 \times 0.5 \mathrm{~cm} 2$ aperture with a conductive sample $0.3 \mathrm{~cm}$ thick, and placed $7.5 \mathrm{~cm}$ from the back wall of the enclosure. Measurement/excitation position at $0.1 \mathrm{~cm}$ from the back wall

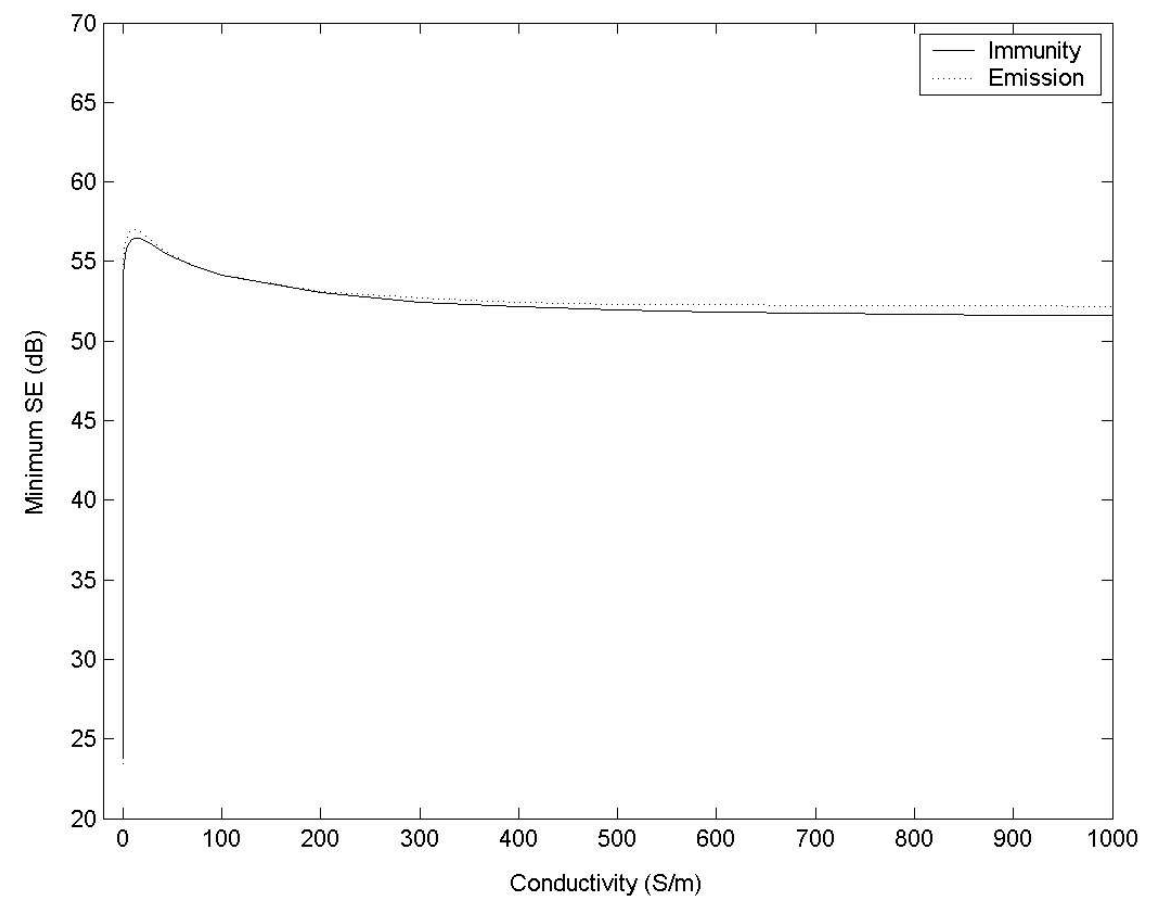

